Short communication

\title{
Scanning electrochemical microscopy determination of hydrogen flux at liquid|liquid interface with potentiometric probe
}

\author{
Justyna Jedraszko ${ }^{a}$, Wojciech Nogala ${ }^{a}$, Wojciech Adamiak ${ }^{a}$, Hubert H. Girault ${ }^{b}$, Marcin Opallo ${ }^{a, *}$ \\ a Institute of Physical Chemistry, Polish Academy of Sciences, Warsaw, Poland \\ b LEPA, Station 6, Ecole Polytechnique Federale de Lausanne, Lausanne, Switzerland
}

\section{A R T I C L E I N F O}

\section{Article history:}

Received 26 January 2014

Received in revised form 20 February 2014

Accepted 7 March 2014

Available online 14 March 2014

\section{Keywords:}

Hydrogen potentiometric sensor

Hydrogen evolution reaction (HER)

Liquid-liquid

Decamethylferrocene

Scanning electrochemical microscopy (SECM)

Reversible hydrogen electrode (RHE)

\begin{abstract}
A B S T R A C T
Scanning electrochemical microscopy potentiometric determination of local hydrogen concentration and its flux next to the liquid|liquid interface was demonstrated. This method is based on the shift of open circuit potential of Pt-based reversible hydrogen electrode. The detection system was verified with a system generating hydrogen under galvanostatic conditions. Then, it was applied to aqueous|1,2-dichloroethane interface where hydrogen is produced with decamethylferrocene as electron donor.
\end{abstract}

(C) 2014 Elsevier B.V. All rights reserved.

\section{Introduction}

The interfaces between two immiscible electrolyte solutions (ITIES) $[1,2]$ offer a new perspective for reactions catalyzed by molecular or nanostructured catalysts. Recently, it has been shown that hydrogen evolution reaction (HER) occurs at the 1,2-dichloroethane (DCE)| water interface under anaerobic conditions, with decamethylferrocene (DMFc) as a reducing agent present in the organic phase [3-5]. This reaction is significantly accelerated by the presence of micro- or nanoparticles [6,7].

Determination of hydrogen concentration and flux next to the heterogeneous reaction zone is crucial for the fundamental studies of HER at a liquid|liquid interface. Although there are numerous methods of sensitive hydrogen detection [8-10], only scanning electrochemical microscopy (SECM) allows determining a flux of this analyte generated at ITIES [11]. SECM amperometric detection of hydrogen produced by proton reduction was earlier reported [12-16]. Here, we propose a SECM-tip potentiometric sensor based on reversible hydrogen electrode $[17,18]$ and its application for hydrogen sensing next to a liquid|liquid (1,2-dichloroetane|water) interface. This approach is more advantageous for this task than amperometric detection due to the lack of analyte consumption.

\footnotetext{
* Corresponding author. Fax: +4822343 3333.

E-mail address: mopallo@ichf.edu.pl (M. Opallo).
}

Moreover, contrary to the amperometric one, a potentiometric hydrogen microsensor does not produce additional proton flux allowing pure generation-collection measurements without feedback at shorter probe-to-sample distances. This is especially suitable for study of hydrogen generation at 1,2-dichloroetane|water interface.

\section{Experimental}

\subsection{Chemicals}

Decamethylferrocene (DMFc, 99\%) was obtained from ABCR. Bis(triphenylphosphoranylidene)ammonium tetrakis (pentafluorophenyl)borate (BATB) was prepared by metathesis of bis(triphenylphosphoranylidene)ammonium chloride (Sigma-Aldrich) and lithium tetrakis(pentafluorophenyl)borate (LiTB) (ABCR) following the procedure described earlier [19] and recrystallized twice from acetone. 1,2Dichloroethane (DCE, $>99 \%+$ ), and $\mathrm{HClO}_{4}(70 \%)$ were obtained from Sigma-Aldrich. $\mathrm{NaClO}_{4}$ (98\%) was purchased from Fluka. All aqueous solutions were prepared with water purified by ELIX system (Millipore). Argon (5.0 N) was from Multax.

\subsection{Apparatus and procedures}

Pt disk microelectrode for SECM experiments was made by sealing a Pt wire (100 $\mu \mathrm{m}$ diameter, Mint of Poland) using PC-10 micropipette puller (Narishige) into borosilicate glass capillaries and 
polished. All electrochemical measurements (cyclic voltammetry and zero current potentiometry) were carried out with a microelectrode patch-clamp amplifier MultiClamp 700B (Molecular Devices). Position of the microelectrode was controlled by a scanning electrochemical microscope CHI900B (CHInstruments). The Pt tip and Pt disk electrode (2 mm diameter, CHInstruments) were used as working electrodes. They were polished with $1,0.3$ and $0.05 \mu \mathrm{m}$ alumina slurry, rinsed and sonicated in demineralized water and ethanol. $\mathrm{Ag}|\mathrm{AgCl}| \mathrm{KCl}(3 \mathrm{M})$ reference electrode was connected to electrochemical cell through a salt bridge filled with the same solution as electrochemical cell in order to prevent chloride contamination. All potentials in this paper are recalculated versus the potential of the reversible hydrogen electrode (RHE), determined as the potential of a Pt electrode being in contact with hydrogen bubbles under atmospheric pressure and used electrolyte $\left(-276 \mathrm{mV}\right.$ vs. reference in $\left.0.1 \mathrm{M} \mathrm{HClO}_{4}\right)$. All solutions were deaerated with argon for $60 \mathrm{~min}$ before experiments. The electrochemical cell or a vial with ITIES together with electrodes and connecting wires were inserted into a bigger glass beaker covered tightly with parafilm with a little hole for SECM tip. Humidified argon $(<1 \mathrm{ppm}$ $\mathrm{O}_{2}$ ) was delivered to the bottom of the beaker in order to maintain oxygen free conditions in the studied system. Proper deoxygenation is crucial for reliable measurements of RHE potentials due to much higher potential of oxygen electrode at the same $\mathrm{pH}$. Both the electrochemical cell and the amplifier head-stages were enclosed in a grounded Faraday cage. All measurements were performed at room temperature (23 \pm $\left.2{ }^{\circ} \mathrm{C}\right)$.

\section{Results and discussion}

\subsection{Sensor verification}

In order to verify the sensor, experiments with controlled electrochemical generation of hydrogen were performed. A Pt microelectrode was placed above the surface of a Pt disk electrode fixed in the bottom of the cell filled with $0.1 \mathrm{M} \mathrm{HClO}_{4}$ and $5 \mathrm{mmol} \cdot \mathrm{dm}^{-3} \mathrm{LiTB}$ in water. The hydrogen was generated by reduction of protons at the bottom electrode connected to the second channel of the amplifier set as "current clamp" in order to maintain galvanostatic conditions. Current values applied to that electrode were adjusted to obtain a similar magnitude of current density of cathodic HER as corresponding to hydrogen flux estimated in a preliminary experiment with HER at the liquid|liquid interface. Constant hydrogen generation rates at a $2 \mathrm{~mm}$ dia. Pt electrode were achieved by galvanostatic polarization at $-80,-100$ and $-150 \mathrm{nA}\left(2.55,3.18\right.$ and $\left.4.77 \mu \mathrm{A} \cdot \mathrm{cm}^{-2}\right)$. Hydrogen activity which is equal to hydrogen concentration $\left(\left[\mathrm{H}_{2}\right]\right)$ in diluted (ideal) solution in the vicinity of the approaching microelectrode was estimated from its open circuit potential (OCP) measured using the first channel of the patch-clamp amplifier set to "zero current clamp". The measured residual current $<1 \mathrm{pA}$ corresponds to $<13 \mathrm{nA} \cdot \mathrm{cm}^{-2}$ at a $100 \mu \mathrm{m}$ diameter electrode. Such a current density is low enough to maintain OCP of RHE dependent on hydrogen partial pressure $\left(p\left(\mathrm{H}_{2}\right)\right.$ according to Nernst equation [20]:

$\mathrm{OCP}=E_{\mathrm{RHE}}-\frac{\mathrm{RT}}{2 \mathrm{~F}} \ln \left(p\left(\mathrm{H}_{2}\right)\right)$

where $E_{\mathrm{RHE}}$ is potential of reversible hydrogen electrode, i.e. that of a Pt electrode in solution with $\mathrm{H}_{2}$ at $1 \mathrm{~atm}$ and $\mathrm{pH}$ as used (not standard hydrogen electrode (SHE) where $\mathrm{pH}$ is 0 ). $\left[\mathrm{H}_{2}\right]$ can be calculated from Henry's equation [21]:

$\left[\mathrm{H}_{2}\right]=\frac{p\left(\mathrm{H}_{2}\right)}{k_{\mathrm{H}}}$ using the value of Henry's law constant for hydrogen equal to $1282 \mathrm{dm}^{3} \cdot \mathrm{atm} \cdot \mathrm{mol}^{-1}[22]$ as:

$\left[\mathrm{H}_{2}\right]=\frac{\exp \left(-\frac{\left(\mathrm{OCP}-E_{\mathrm{RHE}}\right) 2 \mathrm{~F}}{\mathrm{RT}}\right)}{k_{\mathrm{H}}}$.

Potentiometric probe approach curves to a Pt disk generating hydrogen at different rates were used to calculate the distance dependences of $\left[\mathrm{H}_{2}\right]$ using Eq. (3) (Fig. 1, curves 1-3). These dependences are approximately linear for short distances and indicate that a sub-micromolar $\left[\mathrm{H}_{2}\right]$ can be determined by this method. Determination of such $\left[\mathrm{H}_{2}\right]-$ distance dependences cannot be done with an amperometric probe due to the positive feedback influence (additional flux of sample substrate from the amperometric probe). From the Fick's first law:

$J_{\mathrm{H} 2}=-D_{\mathrm{H} 2}\left(\delta\left[\mathrm{H}_{2}\right] / \delta x\right)$

where $D_{\mathrm{H} 2}$ is diffusion coefficient of hydrogen $\left(4.5 \times 10^{-5} \mathrm{~cm}^{2} \cdot \mathrm{s}^{-1}\right)$ [23], and $\left(\delta\left[\mathrm{H}_{2}\right] / \delta x\right)$ is the concentration gradient of $\mathrm{H}_{2}\left(\left[\mathrm{H}_{2}\right]\right.$-distance curve slope), one can calculate the flux of hydrogen $\left(\mathrm{J}_{\mathrm{H} 2}\right)$. The corresponding current densities were calculated according to the Faraday's laws of electrolysis [21]:

$j=2 \mathrm{~F} J_{\mathrm{H} 2}$

where 2 is the number of electrons transferred per $\mathrm{H}_{2}$ molecule and $\mathrm{F}$ is the Faraday constant. The results obtained from the approach curves $\left(2.53,3.29\right.$ and $\left.4.99 \mu \mathrm{A} \cdot \mathrm{cm}^{-2}\right)$ are in good accordance $(<5 \%$ deviation) with the currents applied to the test sample (Pt disk) by galvanostated channel of the patch-clamp amplifier.

\subsection{SECM measurement at ITIES}

The developed sensor was applied to determine the concentration profiles of $\mathrm{H}_{2}$ generated at a liquid|liquid interface (Fig. 1, curve 4 and Fig. 2). In order to push protons into the organic phase, the studied system consists of $5 \mathrm{mmol} \cdot \mathrm{dm}^{-3} \mathrm{LiTB}$ in $0.1 \mathrm{~mol} \cdot \mathrm{dm}^{-3}$ aqueous $\mathrm{HClO}_{4}$ on the top and $5 \mathrm{mmol} \cdot \mathrm{dm}^{-3}$ DMFc (Fig. 1, curve 4 ) or $50 \mathrm{mmol} \cdot \mathrm{dm}^{-3}$ DMFc (Fig. 2) in DCE on the bottom. Organic phase also contained $5 \mathrm{mmol} \cdot \mathrm{dm}^{-3}$ BATB in both cases [3]. The common ion $\mathrm{TB}^{-}$provides

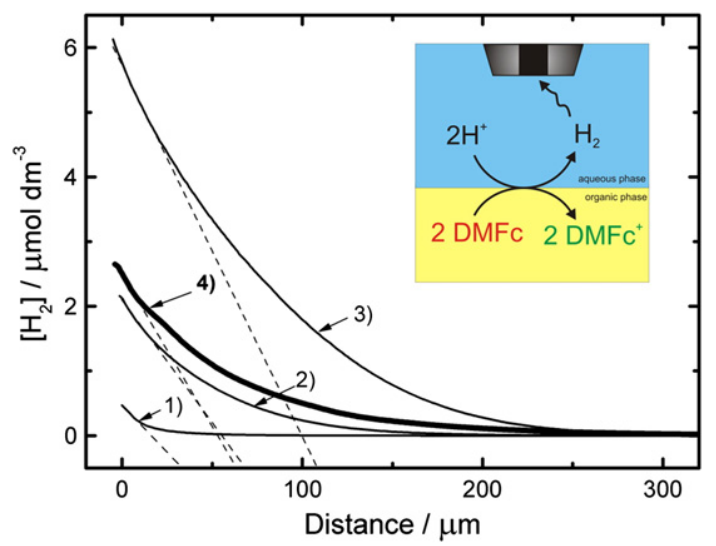

Fig. 1. Hydrogen concentration profiles above $2 \mathrm{~mm}$ dia. Pt electrode polarized galvanostatically at -80 (line 1$),-100$ (line 2), $-150 \mathrm{nA}$ (line 3 ), and above the liquid|liquid interface between $5 \mathrm{mmol} \cdot \mathrm{dm}^{-3} \mathrm{DMFC}+5 \mathrm{mmol} \cdot \mathrm{dm}^{-3}$ BATB in DCE and $0.1 \mathrm{~mol} \cdot \mathrm{dm}^{-3} \mathrm{HClO}_{4}+5 \mathrm{mmol} \cdot \mathrm{dm}^{-3} \mathrm{LiTB}$ in water (curve 4). Curves recalculated from potentiometric approaches recorded at $1 \mu \mathrm{m} \cdot \mathrm{s}^{-1}$ (see text for details). Inset: scheme of detection of $\mathrm{H}_{2}$ generated at liquid|liquid interface. 


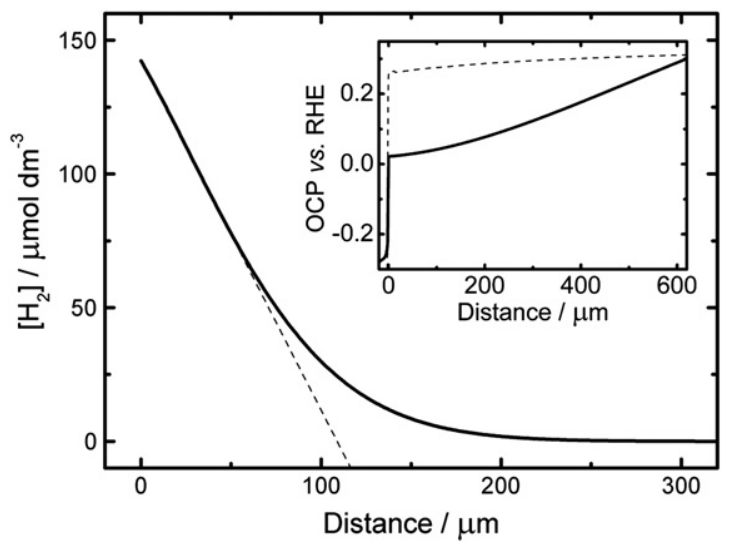

Fig. 2. Hydrogen concentration profile above the liquid|liquid interface between $50 \mathrm{mmol} \cdot \mathrm{dm}^{-3}$ DMFc $+5 \mathrm{mmol} \cdot \mathrm{dm}^{-3}$ BATB in DCE and $0.1 \mathrm{~mol} \cdot \mathrm{dm}^{-3} \mathrm{HClO}_{4}+$ $5 \mathrm{mmol} \cdot \mathrm{dm}^{-3} \mathrm{LiTB}$ in water. Curve recalculated from potentiometric approach shown in the inset (solid line). Dashed line in the inset shows potentiometric approach curve recorded at $\mathrm{pH} \sim 7\left(\mathrm{HClO}_{4}\right.$ replaced by $\left.\mathrm{NaClO}_{4}\right)$. Approaching rate: $1 \mu \mathrm{m} \cdot \mathrm{s}^{-1}$ (see text for details).

negative polarization of ITIES ( $\Delta_{\mathrm{W}}^{\mathrm{DCE}} \phi_{T B^{-}}^{\mathrm{o}}=-0.69 \mathrm{~V}$ [24]) allowing proton transfer from aqueous to DCE phase $\left(\Delta_{\mathrm{W}}^{\mathrm{DCE}} \phi_{H^{+}}^{\mathrm{o}}=-0.55 \mathrm{~V}[4]\right)$. Then overall $\mathrm{H}_{2}$ generation process can be described as follows [3,4]:

$2 \mathrm{DMFc}_{(\mathrm{DCE})}+2 \mathrm{H}_{(\mathrm{W})}^{+}+2 \mathrm{~TB}_{(\mathrm{W})}^{-} \rightarrow 2 \mathrm{DMFc}_{(\mathrm{DCE})}^{+}+\mathrm{H} 2_{(\mathrm{g})}+2 \mathrm{~TB}_{(\mathrm{DCE})}^{-}$

and the proton transfer from aqueous to organic phase is a requisite for this reaction to occur $[3,4]$. In these experiments, both the Pt SECM tip and the reference electrode were immersed in the aqueous phase. The probe approach curves to the liquid|liquid interfaces show $\left[\mathrm{H}_{2}\right]$ increase in the diffusion layer of hydrogen indicating $\mathrm{H}_{2}$ generation from the ITIES. The substantial drop of the probe OCP close to zero distance (Fig. 2, inset) is seen due to insertion of the tip into organic phase containing DMFc. The similar calculations as done above for the sensor verification give the values of $\mathrm{H}_{2}$ flux equal to $2.13 \times 10^{-11} \mathrm{~mol} \cdot \mathrm{cm}^{-2} \cdot \mathrm{s}^{-1}$ when DMFc concentration in DCE was $5 \mathrm{mmol} \cdot \mathrm{dm}^{-3}$ and $5.91 \times 10^{-10} \mathrm{~mol} \cdot \mathrm{cm}^{-2} \cdot \mathrm{s}^{-1}$ when DMFc concentration was $50 \mathrm{mmol} \cdot \mathrm{dm}^{-3}$. This corresponds to the same flux of $\mathrm{H}_{2}$ generated at a planar electrode at 4.1 and $114 \mu \mathrm{A} \cdot \mathrm{cm}^{-2}$, respectively. These experiments show that under the given conditions, $\mathrm{H}_{2}$ flux can be determined close to the liquid|liquid interface. Maximal $\left[\mathrm{H}_{2}\right]$ recorded in our experiments $\left(\sim 0.15 \mathrm{mmol} \cdot \mathrm{dm}^{-3}\right)$ is below its solubility in water under atmospheric pressure $\left(0.85 \mathrm{mmol} \cdot \mathrm{dm}^{-3}\right.$ [25]). This explains why no hydrogen bubbles evolving at the ITIES have been observed. Almost 30 times acceleration of the reaction rate after 10 times increase of DMFc concentration indicates an order of reaction (ca. 1.44) higher than expected (1). This may result from DMFc contaminant acting as a catalyst of the interfacial process. One also has to bear in mind that some fraction of hydrogen dissolves in organic phase. Solubility of $\mathrm{H}_{2}$ in DCE at its $1 \mathrm{~atm}$ partial pressure recalculated from Henry's constant [26] is $2.26 \mathrm{mmol} \cdot \mathrm{dm}^{-3}$. Considering the partition coefficient as the ratio of $\mathrm{H}_{2}$ solubility in DCE to $\mathrm{H}_{2}$ solubility in water (ca. 2.9) and the slightly lower viscosity of DCE (0.84 mPa s), one can estimate the flux of hydrogen in DCE phase being ca. 3.5 times higher than in aqueous phase. Probing of $\mathrm{H}_{2}$ concentration amperometrically in DCE with DMFc is, however, problematic because of the simultaneous DMFc oxidation.

The control experiments without reducing agent in the organic phase (not shown) and with extremely low proton concentration (Fig. 2, inset, dashed line) show no decrease of the OCP when the probe approaches the liquid|liquid interface. This indicates a lack of hydrogen evolution in such conditions.

\section{Conclusions}

We have shown that SECM in potentiometric mode is a suitable method to evaluate fluxes of hydrogen in aqueous solution in a pure generation-collection mode without any feedback influence. This method was applied to determine the fluxes of hydrogen generated at a liquid|liquid interface with decamethylferrocene as the electron donor [3-5]. The proposed method seems to be suitable to other liquid junctions, providing that both oxidized and reduced form of electron donor are not soluble in aqueous phase. The method is not affected by the presence of electron donor in organic phase and it does not produce additional proton flux allowing precise measurements at shorter probeto-sample distances.

\section{Conflict of interest}

None.

\section{Acknowledgments}

This research was supported by the Polish-Swiss Research Programme, project PSPB-035/2010: “Electrocatalysis at droplets”. Support from NanOtechnology, Biomaterials and aLternative Energy Source for the ERA Integration [FP7-REGPOT-CT-2011-285949-NOBLESSE] Project from the European Union is also acknowledged. We wish to thank Dr. Pekka Peljo from LEPA, Ecole Polytechnique Federale de Lausanne for his friendly criticism and suggestions. We are very grateful to the reviewer of earlier version of this manuscript for helpful comments.

\section{References}

[1] H.H. Girault, in: A.J. Bard, C.G. Zoski (Eds.), 1st edn, Electroanalytical Chemistry, A Series of Advances, vol. 23, CRC Press, Boca Raton, 2010, pp. 1-104, (ch. 1).

[2] Z. Samec, Electrochim. Acta 84 (2012) 21.

[3] M.A. Méndez, R. Partovi-Nia, I. Hatay, B. Su, P. Ge, A. Olaya, N. Younan, M. Hojeij, H.H. Girault, Phys. Chem. Chem. Phys. 12 (2010) 15163.

[4] I. Hatay, B. Su, F. Li, R. Partovi-Nia, H. Vrubel, X. Hu, M. Ersoz, H.H. Girault, Angew. Chem. Int. Ed. 48 (2009) 5139.

[5] B. Su, I. Hatay, P.Y. Ge, M. Mendez, C. Corminboeuf, Z. Samec, M. Ersoz, H.H. Girault, Chem. Commun. 46 (2010) 2918.

[6] I. Hatay, P.Y. Ge, H. Vrubel, X. Hu, H.H. Girault, Energy Environ. Sci. 4 (2011) 4246.

[7] X. Bian, M.D. Scanlon, S. Wang, L. Liao, Y. Tang, B. Liu, H.H. Girault, Chem. Sci. 4 (2013) 3432.

[8] T. Hübert, L. Boon-Brett, G. Black, U. Banach, Sens. Actuators B Chem. 157 (2011) 329.

[9] H. Jung, B. Jang, W. Kim, J.-S. Noh, W. Lee, Sens. Actuators B Chem. 178 (2013) 689.

[10] Z. Wang, Z. Li, T. Jiang, X. Xu, C. Wang, ACS Appl. Mater. Interfaces 5 (2013) 2013.

[11] A.J. Bard, M.V. Mirkin (Eds.), Scanning Electrochemical Microscopy, Taylor \& Francis Group, New York, 2012.

[12] P. Bertoncello, Energy Environ. Sci. 3 (2010) 1620.

[13] A.R. Kucernak, P.B. Chowdhury, C.P. Wilde, G.H. Kelsall, Y.Y. Zhou, D.E. Williams, Electrochim. Acta 45 (2000) 4483.

[14] R. Solmaz, A. Doner, G. Kardas, Electrochem. Commun. 10 (2008) 1909.

[15] S. Ahmed, S. Ji, L. Petrik, V.M. Linkov, Anal. Sci. 20 (2004) 1283.

[16] K. Fushimi, K.A. Lill, H. Habazaki, Electrochim. Acta 52 (2007) 4246

[17] Y. Cai, A.B. Anderson, J. Phys. Chem. B 108 (2004) 9829.

[18] C. Iñiguez, R. Zlatev, M. Stoytcheva, B. Valdez, J.-P. Magnin, S. Kiyota, ECS Trans. 33 (2011) 87.

[19] R. Partovi-Nia, B. Su, F. Li, C.P. Gros, J.-M. Barbe, Z. Samec, H.H. Girault, Chem. Eur. J. 15 (2009) 2335.

[20] D.J.G. Ives, G.J. Janz (Eds.), Reference Electrodes: Theory and Practice, Academic Press, New York and London, 1961.

[21] P.W. Atkins, J. de Paulia, Physical Chemistry, Oxford University Press, 2010.

[22] S.A. Khan, S. Duraiswamy, Lab Chip 12 (2012) 1807.

[23] A.F. Mazarei, O.C. Sandall, AIChE J. 26 (1980) 154.

[24] A.J. Olaya, M. Méndez, F. Cortes-Salazar, H.H. Girault, J. Electroanal. Chem. 644 (2010) 60 .

[25] R.C. Weast (Ed.), CRC Handbook of Chemistry and Physics, 67th ed., CRC Press, Boca Raton, FL, 1986

[26] P. Luhring, A. Schumpe, J. Chem. Eng. 34 (1989) 250. 